\title{
Risk Assessment of Fuel Quantity Indicator Replacement in ATR72 Aircraft
}

Journal of Risk and Reliability

000(00):1-13

(CThe Author(s) 2010

Reprints and permission:

sagepub.co.uk/journalsPermissions.nav DOI:doi number

http://mms.sagepub.com

\author{
R. M. Ardito Marretta* \\ Department of Civil and Aerospace Engineering, University of Palermo, Italy
}

\author{
J. A. "Drew" Bedson \\ Daniel Webster College, Nashua, USA
}

\begin{abstract}
Aircraft maintenance activities are rife with opportunities for error. The concurrent in-flight failure of all of the engines of a non-scheduled airline flight and the following lost of human lives highlight one of these opportunities. As commonly recognized among flight operators, each Flight Safety Agency follows the criteria of the ICAO (International Civil Aviation Organization) Annex 16 in which all the evidences of the technical investigation pave the way for avoiding future flight accidents or incidents. On the other hand, when the italian penal procedure code was applied for the Tuninter aircraft ATR72 (identification code TSLBB) crash at issue on 6th August 2005 near Palermo (Italy), the investigation is also carried out for finding (if concurrent or not) the personal and professional responsibilities. This was the task of the first author. Now, this article briefly reports the findings of the investigation and discuss more in detail how both human factors of design and human factors in the published instructions for the completion of a maintenance task contributed to this accident.
\end{abstract}

Keywords

aeronautical risk, aeronautical system reliability, aeronautical system safety, aerospace maintenance, human reliability

\section{Introduction}

On 6th August 2005, an ATR72-202 of a Tunisian airline, during the cruise portion of a non-scheduled flight (TUI 1153) from Bari, Italy (IATA code BRI, ICAO code LIBD) to Djerba, Tunisia (IATA code DJE, ICAO code DTTJ), following the concurrent flame-out of both engines, crashed in the ocean northeast of Palermo, Italy at approximately $38^{\circ} 24^{\prime} .160 \mathrm{~N}$ $-013^{\circ} 27^{\prime} .3 \mathrm{E}$.

Fifteen (15) passengers and one (1) cabin attendant crewmember suffered fatal injuries. The remaining occupants sustained a variety of injuries from slight to serious. After the crash, in conformance with the requirements of Articles 449, 428 and 589 of the Italian penal code, paragraphs I and III, the Italian Ministry of Justice set up an inquiry into the causes of the disaster. The authors, in different roles, were given the task of determining the probable cause of accident. The first

*Corresponding author; e-mail: rosario.arditomarretta@unipa.it 
author was the official investigator of the Italian Department of Justice. Then, all the information, the reports and the factual evidences given by the first author are not independent opinions but he was the only one admitted to the non publicly disclosed files and documents of the Italian Department of Justice. From the available data of Flight Data Recorder (FDR), Cockpit Voice Recorder (CVR), flight documentation and subsequent physical examination of the aircraft, the authors found that the aircraft had depleted all of the fuel aboard leading to the concurrent flame out of both engines. This evidence was in opposition with the dramatic pilot communication with Palermo air traffic control (ATC) during the emergency, as recorded by CVR, where the crew declared the presence of $1800 \mathrm{Kg}$ of fuel on board. The performance and maintenance records of the aircraft revealed that a replacement of the fuel quantity indicator was carried out shortly before the accident flight. Further, the records revealed that the newly installed fuel quantity indicator (FQI) was appropriate for installation in the ATR 42 family of aircraft and not the ATR 72 family of aircraft. The different algorithms used by the different fuel quantity indicators of the ATR 72 and ATR 42 coupled with different fuel probes architecture and capacitance (for those families of aircraft) lead to the conclusion that a potential hazard is hidden in this type of maintenance, particularly in the light that in some configurations of ATR 72 the fuel low level signal does not have an independent sensor and circuit. This paper discusses the replacement of the fuel quantity indicator, provides an analysis of the effects of this replacement, reviews alternative installations and ends by making recommendations to mitigate risks in this situation.

During the investigation, the Agenzia Nazionale Sicurezza Volo (ANSV) - Italian Agency for Flight Safety - issued two recommendations (1917/INV/443/5/05, 2818/INV/443/5/05) (1), (2), the manufacturer, Avions de Transport Regional (ATR), issued an All Operators Message (AOM) and the US FAA issued Airworthiness Directive 2005-NM-193-AD (FAA 2005) addressing the possible installation of incorrect Fuel Quantity Indicators in ATR aircraft.

\section{Factual Evidence}

The accident aircraft was built by ATR in March 1992 and delivered to the operator, Tuninter, on 22 April 1992. Prior to the accident the aircraft had accumulated 29,893.5 hours of flight and 35,259 cycles. It had completed its last periodic airworthiness inspection in March of 2004. The particulars of the aircraft are presented in Table 1. There was no evidence of pre-impact structural failure. Because the two Pratt and Whitney 124B turboprop engines suffered a propulsive failure, the first author closely followed the investigation through the complete disassembly and teardown of both engines at the Lufthansa Aero Gmbh facility in Alzey near Frankfurt, Germany.

Although the engines had minor discrepancies, both of the engines were free from defects. In Table 2, summary information regarding the powerplants is shown.

Finding no significant discrepancies with the powerplants, the investigation turned to the fuel supply. The last thorough inspection of the aircraft fuel tanks was conducted on 12 and 13 March 2004 at the ATR facility in Toulouse, France. Video inspection of the fuel tank devices and structure, as required by ATR documents SWAR No. DS/CA - 373/04 and ATR No. DO/IS-637/04 (FH 27318 e CY 31986), was accomplished. In these inspections minor discrepancies were noted. The Italian Air Force laboratory (3) conducted a fuel chemical and physical properties test of the residual fuel found in the fuel filters. No defects were reported.

The investigation turned to the aircraft flight performance and maintenance records. On 5 August 2005, the same crew that operated the accident flight made the following flights (ATR 72 TS-LBB maintenance logbook No. 068297, Fig. 1, and ATR 72 TS-LBB performance record book No. 075635, Fig. 2):

FLT 1140 TUN-CTA (IATA acronyms). For this flight, in the Maintenance Logbook, in the "Complaints" Section, no anomalies were reported; FLT 1141 CTA-TUN (IATA acronyms). For this flight, in the Maintenance Logbook, in the "Complaints" Section, the malfunctioning of FQI is reported (Fig. 1) by the crew, i.e.:

"Subject: INSTRUMENT - "FUEL QTY INDICATOR R TK O/S"; followed by "ACTION TAKEN - Remplace (sic!) fuel Qty, - OFF S/N 179, P/N 748681-2 and ON S/N 0238, P/N 749-158 Indicateur (sic!) OK" 
In accordance with the complaint of the pilot that the fuel quantity indicator for the right wing fuel tank was out of service, the technical staff of the aircraft operator replaced the unusable FQI having P/N 748681-2 with another one with P/N 749-158. This is significant in that P/N 749-158 is pertinent to the ATR 42 aircraft family not the ATR 72 aircraft family. This replacement took place on the day before the accident flight of 6 August 2005.

ANSV investigative report 2818/INV/443/5/05 (2) states that the crew reported that they had $2300 \mathrm{Kg}$ aboard the aircraft on arrival in Bari. To this they added 600 liters (Fig 3) of fuel prior departure from Tunis. The report further states that the crew now had an indicated fuel load of $2700 \mathrm{Kg}$ (2). There is no mention whether the crew conducted a fuel up load verification that volume reported by the fuel vendor was equal to the change in fuel weight displayed on the fuel gauge. Using the common conversion of one (1) liter of turbine fuel weighing $.8 \mathrm{Kg}$, the 600 liters added to the aircraft should have raised the FQI indication by $480 \mathrm{Kg}$ vice the $400 \mathrm{Kg}$ reported. This difference, equal to $20 \%$ of the weight added to the aircraft, could have been an early indication of something amiss with the FQI system.

The Load and Trim sheet for the flight from Tunis to Bari (Fig 4), the flight immediately preceding the accident flight, shows $3770 \mathrm{Kg}$ of fuel aboard for the flight to Bari. Based upon the report of the ANSV, the aircraft had $2300 \mathrm{Kg}$ aboard upon arrival. There is no indication whether the crew conducted a "reasonableness" test of the $1470 \mathrm{Kg}$ fuel burn from Tunis to Bari, a flight of approximately $400 \mathrm{~nm}$. Further, there is no indication whether there was any notice of the fact that if the aircraft just consumed $1470 \mathrm{Kg}$ on a flight of approximately $400 \mathrm{~nm}$ and it would be reasonable to assume that it would use $50 \%$ more fuel for the $600 \mathrm{~nm}$ flight to Djerba or approximately $2200 \mathrm{Kg}$, slightly less than the indicated total fuel aboard the aircraft for the flight to Djerba.

\section{FQI Modular Design}

The ATR 42 and 72 aircraft utilize a similar cockpit panel. The FQI is located in the lower left quadrant of the center panel (Fig 5(a)) for both aircraft. The FQIs for both ATR 72 and ATR 42 (Fig 5(b), Fig5(c)) are built up in an exterior cartridge having the same overall dimensions. The faceplate of both the FQI for the ATR 42 and the ATR 72 have two windows with Light Emitting Diode (LED) displays indicating the quantity (in weight) of the stored fuel in each of the respective wing fuel tanks.

The FQIs incorporate low-level lights which activate a visual and an aural alert when the fuel remaining is equal to a specified amount. In first generation devices, the low-level alerts are activated by the same system that calculates and displays the fuel quantity and is not independent from the computed quantity of fuel reading on the led-windows of the FQI. Later, to meet the Extended Twin-Engine Operations (ETOPS) requirements, the manufacturer of the FQI, Intertechnique, developed a later generation of FQIs in which the low-level signals have an independent circuit. The decision to install this type of fuel quantity indicators is made by the aircraft operator (4), (5), (6), (7) .

Close inspection of the FQIs appropriate to the ATR 42 and the ATR 72 show a similarity among their basic external architectures and the circuital hardware ((Fig 6(a), Fig 6(b), Fig 6(c)).

The type set of the external labeling and the similar part numbers seem to be identical, (Fig 6(a), Fig 6(b), Fig 6(c) and Tables 3, 4).

Differences between the FQI for the ATR 42 and the ATR 72 can be found in the stampings on the faceplates of the FQIs in which the allowable fuel is indicated (Fig 6(a), Fig 6(b), Fig 6(c)) and on the cartridge labels in which the silkscreen of P/N and S/N are shown. The FQIs of the ATR 42 and the ATR 72 allow a universal modularity for each type of cockpit; moreover, the rear plunging connectors (S/N 1004 53T - 2B P, NAS 1599 TYPE 14 - 19 SW; S/N 1004 53T - 3B P) are interchangeable.

This is true of both the first and the second generation of FQI. Anyway, the FQIs of the ATR 42 and the ATR 72 show exterior and interior differences being the former the part/number $(\mathrm{P} / \mathrm{N})$ and serial/number $(\mathrm{S} / \mathrm{N})$ on the cartridge identification label and the hardware circuital components the latter (the values of resistances R20, R21, R41 for the chain 
of diodes MA1, MA2, MA4, MA5 as electronic components of FQI block diagram (Fig 6(b)). These differences are relative to non-ETOPS (Extended-range Twin-engine Operational Performance Standard) FQIs like those of the aircrafts under examination. The circuital differences are linked to the different input signals (and different electronic processing) arising from the tank probes having different capacitances for ATR 72 and ATR 42.

\section{FQI Removal, Installation and Testing}

The procedure for the removal and installation of the FQI and the procedure for the testing of the FQI are specified in manufacturer's documents designated Job Instruction Cards (JIC) ( (6)). The procedure for the removal and installation of the FQI requires, as a final step, the test of the FQI and states "...SEE JOB INSTRUCTION CARD JIC: 284200-TST-10000. JIC 284200-TST-10000 is the procedure for the test of the FQI...". This procedure tests the indicator through a series of "self-test" processes. After the conclusion of the "self-test" procedures the JIC references that the FQI should display the fuel remaining in the respective tanks without any reference to an independent verification of the amount of fuel in the tanks.

\section{Fuel Quantity Probe System}

The design principle of the fuel tank fuel probe system is one based on the capacitance variations associated with the fuel level. The main difference between the probe-set of the two types of aircraft is in the number of probes in the fuel tanks, 5 in each wing fuel tank of the ATR 42 and 6 in each wing fuel tank of the ATR 72.

As noted in figures (Fig 7, Fig 8), the capacitance at the "empty" or minimum point varies significantly between the aircraft types (here only the first probes for both aircrafts are shown). Further, as noted previously, there is an additional probe in the ATR72. Following the line and components chain of Fig 9, one can note the signals from the probes to the FQI. This circuital architecture undergoes slight differences when the independent low-level "warning-lights" signal has to be provided for ETOPS configuration of aircraft (see Fig 10).

When evaluating the empty tank capacitance of the FQI system circuits of the ATR 42 vice the ATR 72 there are noticeable differences whether ETOPS or non-ETOPS (Fig 9, Fig 10). As previously mentioned, these figures sketch the circuital design for non ETOPS and ETOPS FQIs architectures. In non ETOPS FQI (both for ATR42 and 72) the low level electrical signal is running in serial bus with the output tank probes capacitance signals (dependent low-level scheme). In the ETOPS FQI different data bus is processed in parallel and it is not directly dependent on the output tank probes signals. Anyway, this paper deals with the FQIs of ATR42 and 72 of the first type only. When the system capacitance for the FQI system of the ATR 42 and the ATR 72 are summed at the FQI there are significant differences as noted in Fig 11. The data in Fig 11 make a compelling argument for directly evaluating the effect of ATR 72 FQI probe set capacitance when mated with an ATR 42 FQI.

\section{Fuel Quantity Indicator (FQI) Incorrect Replacement Test-Bench Simulation}

To simulate the behavior of an FQI appropriate to an ATR 42 when incorrectly installed into the cockpit of an ATR 72, the following tests were performed in a devoted test-bench (Fig 12) at the Intertechnique facility near Paris, France.

- Verification of the input/output dialog schemes between the FQI Intertechnique S/N 749-158 (ATR42) and the fuel level probes with their relative correlation algorithms

- Verification of the input/output dialog schemes between the FQI Intertechnique S/N 748-681-2 (ATR72) and the fuel level probes with their relative correlation algorithms

- Verification of the input/output dialog schemes between the FQI Intertechnique S/N 749-158 (ATR42) and the fuel level probes with their relative correlation algorithms during an electronic simulation of de-fuelling and re-fuelling 
- Verification of the input/output dialog schemes between the FQI Intertechnique 748-681-2 (ATR72) and the fuel level probes with their relative correlation algorithms during an electronic simulation of de-fuelling and re-fuelling

The fuel probe-set technical references, both for ATR 42 and ATR 72, are provided by Aerospatiale reports No. 419.036/82 (ATR 42) and No. 420.759/85 (ATR 72) ( (8), (9)) and Acceptance Test Procedure (ATP) 7CR-10936 (FQI S/N 749-158 (ATR 42)) ( (10)) and 7CR-10662 (FQI S/N 748-681-2 (ATR 72)) ( (11)).

To understand the relationship between the fuel probe-sets and the FQI displays on the LED-windows in the FQI, or, in other words, the correlation between the probe-set capacitance and the displayed fuel quantity, three procedural steps were performed:

- Step 1) all of the electric circuits of the FQIs were analyzed (i.e., processing circuits of probe-level signals) and their relative differentiations in terms of external markings and of electrical components.

- Step 2) once the components were identified and put in order in accordance with the manufacturer's circuit scheme between the fuel probe-set and FQI, the test-bench was able to give - in the range of probe capacitance variations connected with variable fuel presence in the tanks - the input/output logic between the dielectric capacitance and the real level of fuel, i.e.,

$$
\begin{gathered}
Y=23.67 X-2521.3(A T R 42) \\
Y=17.996 X-2678.2(A T R 72)
\end{gathered}
$$

being $\mathrm{Y}$ the indicated fuel quantity in the tank $(\mathrm{Kg})$ and $\mathrm{X}$ the total amount of fuel probe-set capacitance.

The previous equations have been provided for the referred equipment by Intertechnique, the manufacturer of the FQI, as all the relationships that will be used in the present section.

Eqs (1) and (2) were obtained by the accomplishment of ATP (CR10936 and CR10662) - previously adopted - to both the FQIs (S/N 749-158 (ATR 42) and S/N 748-681-2 (ATR 72)) on the test-bench of Fig 12. These procedures are in compliance with the Joint Aviation Authority (JAA) quality directivities for instrument evaluation (PGQ-1556). In two phases, both of the FQIs were connected to the test-bench equipment. The units were subjected to the calibration tests through a continuous variation of the input capacitance from the fuel probe-set simulators. Roughly speaking, the test-bench is used to process the basic derivation for flux linkages in tubular conductors for finding the flux linkages for both core and sheath of the tank probes according to the formulas:

$$
\lambda_{T}=\lambda_{i}+\lambda_{E}
$$

where $\lambda_{T}, \lambda_{i}$, and $\lambda_{E}$ are the total flux linkage associated with conductor, the flux linkage internal to conductor and the flux linkage external to conductor, respectively. Basically, the above mentioned parameters are linked to the conductor geometrical features (in polar coordinates frames, we say $r, a, b)$ and they depends on the conductor permeability $\mu$, and the current value, $i$, i.e:

$$
\begin{gathered}
\lambda_{i}=\int_{a}^{b} \frac{r^{2}-a^{2}}{b^{2}-a^{2}} \mu \frac{r^{2}-a^{2}}{b^{2}-a^{2}} \frac{i}{2 \pi r} d r \\
\lambda_{i}=\int_{a}^{b} \mu_{\text {out }} \frac{i}{2 \pi r} d r
\end{gathered}
$$

where $\mu_{\text {out }}$ is the permeability of the material external to the conductor. All of the main FQI functions were checked with particular reference to the indicated fuel presence in the tank and its low-level detection (lights "ON").

- Step 3) Once the prescribed ATP parameters were accomplished, the simulation of an incorrect replacement (simulation of the installation of a FQI appropriate to an ATR 42 into an ATR 72) was conducted in the test-bench through the testing the FQI 749158 of ATR 42 (instead of FQI 748681-2 for ATR 72). At this point, the input signal for this FQI 
(FQI 749158 of ATR 42) was the total capacitance arising from the fuel probe-set of the ATR 72. From the given partial capacitances, one obtains the total capacitance be equal to $144.7 \mathrm{pF}$ with (real/virtual zero quantity of fuel on board). When this value of capacitance (for ATR 72) was processed by the test-bench into the FQI (ATR 42), the FQI indicated a fuel quantity of $910 \mathrm{Kg}$ and $890 \mathrm{Kg}(910 \mathrm{Kg}$ and $890 \mathrm{Kg}$ of fictitious fuel in the left and right tanks, respectively). Following the same procedure, the range of capacitance values (from empty to full tank configurations) the "mismatching FQI" law was obtained and is shown in Fig 13.

These tests were conducted three (3) times with no variation in data.

\section{Fuel Low Level Alerting Consideration}

The design of the ATR 42 and the ATR 72 are in conformance with international regulation. Neither United States 14 Code of Federal Regulations Part 25 (14CFR25) or European Aviation Safety Agency (EASA) Certification Specification 25 Large Aeroplanes (superseding JAR-25) require the installation of fuel low level alerting systems independent from the fuel quantity measuring system. In some cases manufacturers, ATR included, have developed fuel low level alerting systems independent from the fuel quantity measuring systems. In the case of TU1153, the ANSV determined that, "...had there been the alternate independent fuel low level alerting system approved by ATR for installation in the ATR 72 installed in the accident aircraft, twice during the day of the accident the system would have alerted the crew to a low fuel situation..." ( (2)). The flight crew was not alerted to the low fuel condition and missed an important opportunity to prevent the accident.

\section{Human Factor Considerations}

The ATR 42/72 family of aircraft is designed with a high degree of commonality. ATR describes the ATR42/72 aircraft family as having an "interchangeability of parts and mechanisms" ( (7)). In the case of the ATR 42 FQI, part number 749-158, the unit was physically interchangeable with ATR 72 FQI part number 748681-2. Because the units were interchangeable the maintenance technicians of the operator were able to install the incorrect unit. The shape and interchangeability of line replaceable units (LRUs) is an on-going concern in the human factors of maintenance community. "...The complexity of maintenance error can range from errors as simple as a maintenance technician forgetting to torque a finger-tightened screw to some deficiency in the design of the aircraft or the management of the maintenance process. The maintenance community has become adept at dealing with these errors through redesign and process change. For example, units such as gauges, communication and navigation units, etc., which do not require taking the aircraft to the maintenance hangar for replacement (line replaceable units), are currently being designed with different size or shape electrical and fluid connectors so that cross-connection errors upon reassembly are eliminated..." ( (12)). This is not the case with the ATR FQI. The modular design of the ATR72 FQI, with minor distinguishing features, contributes little to reduce the possibility of incorrect installation once the incorrect unit has been selected. Absent distinguishing features to prevent the incorrect installation, it is the expectation of the technician that the part he just installed was the correct one.

Reason has developed what he calls the "Generic Error-Modelling System (GEMS) ( (13)). The scheme of Table 5 summarizes a portion of Reason's GEMS. He describes errors as being skill-based, rule-based or knowledge-based. According to Reason, skill-based errors are those errors that occur during familiar, routine actions, using pre-existing mental models that may be automatically performed once initiated and usually having predictable errors caused by technician actions. An example could be damage to a fastener made by a technician who selected and used the incorrect size of wrench. Rule-based errors are those errors that occur during less familiar tasks involving problem solving activities, using pre-existing rules (or procedures) and usually have predictable errors often associated with a failure to follow the rules or the omission of a step in a procedure. An example could be the failure of a technician to verify the applicability of a part. Knowledge-based errors are those errors that occur during unfamiliar problem solving activities where the technician is engaged in a conscious process to solve the problem and where error types vary. The maintenance technicians of the operator 
were conducting a reasonably familiar problem solving task (removal and replacement of a cockpit indicator). According to Reason, this type of task predictably has rules-based errors where familiarity with the task dominates the chance of error and the ease of error detection may be difficult ( (13), (14),). The ATR FQI units are of a similar color and coding. Manufacturers and operators need to consider the interaction of the users in the design of devices, systems and maintenance practices. As noted by the United States Food and Drug Administration, "...A person's most basic physical and sensory capabilities include vision, hearing, manual dexterity and reach. A number of related design factors can interact with them to influence human performance: the legibility and discriminability of displayed symbols, audibility and distinctiveness of alarms, the strength required to make connections and the requirements for reaching controls..." (emphasis by the authors) ( (15)). To reduce the opportunity for incorrect installation and/or the making of incorrect connections in medical devices, the US Food and Drug Administration recommends that "...If a hazard cannot be eliminated by design solution, color codes or other markings will help the user achieve proper connections and component or accessory installation..." ( (15)). This is sound advice for the designers of both medical devices and aircraft components. Aviation maintenance human factors experts recommend that error reduction strategies (those strategies incorporated into the maintenance system to prevent error at the point of work such as improved lighting, improved component marking and access, and better training) be complemented by error capturing (those strategies incorporated into the maintenance system to trap errors before errors can make it into the air transportation system such as between task inspections, post task inspections, independent verification tasks and functional tests). The Job Instruction Card for the replacement of the FQI did not clearly state the need for an independent verification of the fuel aboard the aircraft as part of the FQI functional verification following replacement, an important error trapping strategy.

It is apparent from the preceding discussion that aviation is an elaborate system involving the complex interaction of humans and machines. "...Since people design, build, operate, maintain, and manage potentially hazardous technologies, it is hardly surprising that their decisions and actions contribute, one way or another, to virtually all unwanted events..." ( (16)) "...Human and organizational factors now dominate the risks to aviation, and have done so for at least two decades..." ( (17)).

"...Safety Management Systems provide a formal, organized process whereby people plan, perform, assess, and improve the safe conduct of work..." ( (18)). Safety Management Systems (SMS) facilitate the orderly development and management of safe practices across the organization. In general, SMS use four cornerstones as a foundation; philosophy, policy, procedure and practice. That is, the organization must have made a philosophical decision that risk exists and that the organization acknowledges its responsibility to manage that risk, that the organization will include safety favorable structures and safety goals in all of its policies, that the organization wants people to use those procedures that encourage safety and that the on-the-job practices of the organization match with the stated focus on safe operations. The comprehensive management of safety includes an organization wide focus on the concept that safety is good for the organization and that safety is everyone's responsibility.

\section{Recommendations}

The authors make the following recommendations specifically in response to this accident: to ATR:

1. Modify the Job Instruction Card for the removal and installation of the FQI to include a caution statement indicating the possibility of installing the incorrect unit in the aircraft.

2. Modify the Job Instruction Card for the removal and installation of the FQI to include a task to verify the amount of fuel aboard the aircraft by using an alternate system such as the wing mounted magna-sticks. 
3. Modify the Job Instruction Card for the removal and installation of the FQI to include a reference to the appropriate card and task for determining fuel load using the wing mounted magna-sticks, or other independent method for determining fuel quantity.

4. Modify the Job Instruction Card for the test of the fuel quantity indicator to include a caution statement indicating the possibility of the installation of the incorrect unit in the aircraft.

5. Modify the Job Instruction Card for the test of the fuel quantity indicator to include a task to verify the amount of fuel aboard the aircraft by using an alternate system such as the wing mounted magna-sticks.

6. Modify the Job Instruction Card for the test of the fuel quantity indicator to include a reference to the appropriate card and task for determining fuel load using the wing mounted magna-sticks, or other independent method for determining fuel quantity.

7. Develop a system to incorporate a highly visible labeling system for the case of the FQI indicating that the unit is appropriate for the ATR 42 only or the ATR 72 only. This system should be expanded to cover all ATR components where the possibility of installation in the wrong model of aircraft is possible.

8. Review the documentation produced by ATR and provided to technicians for other instances where the inter-modular design of components creates the opportunity for the physical installation of a component inappropriate for the type of aircraft and, where appropriate, incorporate the recommendations above.

to Regulatory authorities:

1. Require all operators remind their employees of the need to verify applicability of all components by an approved method.

2. Recommend all operators of transport aircraft to remind their employees of the need to verify the correct operation of systems, particularly fuel quantity measuring systems, following repair or replacement. This verification shall be by an approved method.

3. Require all future aircraft transport category aircraft to be designed with fuel low level warning systems independent from the fuel gauging systems.

to the Operator:

1. Establish a comprehensive program of verifying that the fuel added to the aircraft during refueling operations matches with the change in fuel quantity aboard the aircraft and, when differences occur, a specified procedure is used for determining the cause of the difference.

2. Conduct reinforcement training for all technicians and materiel personnel of the methods to conduct, and the need for, meticulous verification of component applicability for installation.

3. Verify that a comprehensive safety management system (SMS), in accordance with international standards, is in place and used.

\section{Conclusions}

This paper analyzed the reasons for the occurrence of a fatal aircraft accident. The reported analysis is based on the direct involvement of one of the authors in the related crash investigations, that gave him opportunities to access all the available data and files evidence. The presented discussion has shown how aircraft poorly managed maintenance activities can easily become sources of fatal errors. The analyzed specific dramatic accident, involving the concurrent in-flight failure of all of the engines of a non-scheduled airline flight, exemplified such possibility. On the basis of the discussed analysis, the authors have given a series of recommendations to avoid future occurrence of similar episodes. Finally, the paper has once again shown how aviation maintenance systems are complex combinations of machines and technicians. Research into how technicians 
interpret data, identify solutions and accomplish tasks shows that even when experts complete work assignments, they may make errors. To the extent possible, aircraft operations, aircraft components, maintenance procedures and inspection procedures should be designed with this understanding. As stated by James Reason and Alan Hobbs, "...Unless you manage error effectively ... error will manage you..."

\section{Acknowledgements}

The authors acknowledge the encouragement, support and assistance of the Ministry of Justice, Italy, the ANSV, ATR, Lufthansa Gmbh, and Intertechnique, without which we would not have been able to complete our work and whose interests in the safe operations of aircraft cannot be overstated. And, finally, the authors apologize for the quality of some of the printed documents shown in the figures of this paper. Many of them are scanned copies of the original documents included in the final investigation report of the Italian Magistrates and were found in the cockpit of the aircraft following its recovery from approximately $1400 \mathrm{~m}$ below sea level.

\section{References}

[1] ANSV. Safety Recommendation. Rome, Italy: ANSV; 2005. 1917/INV/443/5/05.

[2] ANSV. Safety Recommendation. Rome, Italy: ANSV; 2005. 2818/INV/443/5/05.

[3] IAF. Chemical Report. Pratica di Mare, Rome, Italy: Italian Air Force; 2005. 05/237.

[4] ATR. Air Service Bulletin. Toulouse, France: ATR; 2005. ATR42-28-0033.

[5] ATR. Air Service Bulletin. Toulouse, France: ATR; 2005. ATR72-28-1013.

[6] ATR. Removal/Installatio of FQI. Toulouse, France: ATR; 2005. JIC 28-4281 RAI 10000.

[7] ATR. Test of FQI. Toulouse, France: ATR; 2005. JIC 28-42-00 TST 10000.

[8] Aerospatiale. Technical Report. Toulouse, France: Aerospatiale; 1982. 419.036/82-ATR42.

[9] Aerospatiale. Technical Report. Toulouse, France: Aerospatiale; 1985. 420.759/85-ATR72.

[10] Intertechnique. Technical Report. Plaisir Cedex, France: Intertechnique; 1996. ATP 7CR-10936 FQI S/N 749-158-ATR42.

[11] Intertechnique. Technical Report. Plaisir Cedex, France: Intertechnique; 1996. ATP 7CR-10662 FQI S/N 748-681-2-ATR72.

[12] UKCAA. Human Factors in Aircraft Maintenance and Inspection. West Sussex, UK: UK Civil Aviation Authority; 1996. CAP 718.

[13] Reason JT. Human Error. Cambridge, UK: Cambridge University Press; 1990.

[14] Reason JT. Human Factors Aspects of Safety Management Systems. Washington, DC, USA: US FAA Federal Aviation Authority; 2001. available on line @ http://hfskyway.faa.gov/HFAMI.

[15] Sawyer R. Do it by Design, an Introduction to Human Factors in Medical Devices. Washington, DC, USA: U.S. Food and Drug Administration; 1996. 28-36.

[16] Reason MME J T. Human Factors Guide for Aviation Maintenance. Washington, DC, USA: US FAA Federal Aviation Authority; 1998. available on line @ http://hfskyway.faa.gov/HFAMI.

[17] USDE. Safety Management System Policy. Washington, DC, USA: U.S. Department of Energy; 1996. USDE8024.

[18] Hobbs RJT A. Managing Maintenance Error: A Practical Guide. Aldershot, UK: Ashgate Publishing Ltd; 2003. 
Table 1. ATR 72 TSLBB basic info on 05 august 2005

\begin{tabular}{ccc}
\hline No. & Data & Description \\
\hline 1 & Register & TS-LBB \\
2 & Version & ATR72-202 \\
3 & Builder & Avions De Transport Regional, France \\
4 & Serial number & 258 \\
& Manufactoring & march 1992 \\
5 & Delivery & $22-$ apr- 92 \\
6 & Operator & Tuninter \\
7 & Owner & Tuninter \\
8 & Employment & Transport \\
9 & Total flight hours & $29,893: 30$ \\
10 & Cycles & 35,259 \\
11 & Since last overhaul (and type) & "C" Type 6 march 2004 \\
12 & Extimated next overhaul (and type) & "C" Type before 1,427 hours \\
13 & Hours for each "C" type overhaul & 4,000 hours \\
14 & Airworthiness Expiration & 27 december2005 \\
\hline
\end{tabular}


Table 2. Powerplants basic info

\begin{tabular}{lrrrrr}
\hline & \multicolumn{2}{c}{ Engines } & & \multicolumn{2}{c}{ Propellers } \\
\cline { 2 - 3 } \cline { 5 - 6 } Position & $\# 1$ (left) & $\# 2$ (right) & & $\# 1$ (left) & $\# 2$ (right) \\
S/N & 124638 & 124557 & & 911028 & 910107 \\
Manufacture & march'93 & march'92 & & nov.'91 & feb. '91 \\
Working (hrs) & 18151,04 & 21504,96 & & 23410,94 & 20617,35 \\
Cycles & 21430 & 25505 & & 27336 & 24415 \\
Since last overhaul (hrs) & 1385,04 & 2244,96 & & 5863,94 & 2962,35 \\
Cycles since last overhaul & 1763 & 2858 & & 7099 & 3791 \\
Next overhaul (hrs) & 6614,96 & 5755,04 & & 4636,06 & 7537,65 \\
Potential next overhaul (hrs) & 8000 & 8000 & & 10500 & 10500 \\
\hline
\end{tabular}


Table 3. ATR 42 FQI common $\mathrm{P} / \mathrm{N}$ between ATR 42 and ATR 72 (yellow areas)

\begin{tabular}{lcc}
\hline ITEM & P/N & Qty \\
\hline Cockpit indicator & $748465-5(\mathrm{Kg})$ & 1 \\
& $\begin{array}{c}748522-2(\mathrm{Lbs}) \\
\end{array}$ & \\
& $749158(\mathrm{Kg})$ & \\
& $749159(\mathrm{Lbs})$ & \\
& $749758(\mathrm{~Kb})$ & \\
\hline Junction box & $796950-1$ & 2 \\
\hline Preselector & $796966(\mathrm{Kg})$ & 1 \\
& $796967(\mathrm{Lbs})$ & \\
\hline Indicator repeator & $748722(\mathrm{Kg})$ & 1 \\
& $748724(\mathrm{Lbs})$ & \\
\hline Fuel Probes & 798038 & 2 \\
& $766046-2$ & \\
& $766047-2$ & \\
& $766048-2$ & \\
\hline In Tank Harness & 768055 & 2 \\
\hline
\end{tabular}


Table 4. ATR 72 FQI common $\mathrm{P} / \mathrm{N}$ between ATR 42 and ATR 72 (yellow areas)

\begin{tabular}{|c|c|c|}
\hline ITEM & $\mathrm{P} / \mathrm{N}$ & Qty \\
\hline Cockpit indicator & $\begin{array}{c}748681-2(\mathrm{Kg}) \\
748682-2(\mathrm{Lbs}) \\
749160(\mathrm{Kg}) \\
749161(\mathrm{Lbs}) \\
749759(\mathrm{Kg}) \\
749760(\mathrm{Lbs})\end{array}$ & 1 \\
\hline Junction box & $796950-1$ & 2 \\
\hline Preselector & $\begin{array}{c}796984(\mathrm{Kg}) \\
796979(\mathrm{Lbs})\end{array}$ & 1 \\
\hline Indicator repeator & $\begin{array}{l}748722(\mathrm{Kg}) \\
748724(\mathrm{Lbs})\end{array}$ & 1 \\
\hline Fuel Probes & $\begin{array}{c}766983-1 \\
766793-1 \\
766795-2 \\
766796-2 \\
768100 \\
766797-2\end{array}$ & 2 \\
\hline In Tank Harness & $\begin{array}{l}798017-3 \\
796977-2 \\
796947-3 \\
796948-3 \\
798078-2 \\
796949-3\end{array}$ & 2 \\
\hline High Sevel Sensor & $722139-1$ & 2 \\
\hline
\end{tabular}


Table 5. Scheme of summary of portions of Reason's GEMS

\begin{tabular}{|c|c|c|c|}
\hline \multicolumn{3}{|c|}{ Scheme of summary of portions of Reason's GEMS } & \multirow[b]{2}{*}{$\begin{array}{l}\text { Knowledge-based } \\
\text { Errors }\end{array}$} \\
\hline Dimension & Skill-based Errors & Rule-based Errors & \\
\hline Type of Activity & Routine Activities & $\begin{array}{l}\text { Problem Solving Activi- } \\
\text { ties }\end{array}$ & $\begin{array}{l}\text { Problem Solving Activi- } \\
\text { ties }\end{array}$ \\
\hline Focus of Attention & $\begin{array}{l}\text { On something other than } \\
\text { the problem at hand }\end{array}$ & On the problem & On the problem \\
\hline Control Mode & $\begin{array}{l}\text { Primarily by automatic } \\
\text { process (schemata) }\end{array}$ & $\begin{array}{l}\text { Primarily by automatic } \\
\text { process (stored rules) }\end{array}$ & Conscious process \\
\hline $\begin{array}{l}\text { Predictability of Error } \\
\text { Types }\end{array}$ & $\begin{array}{l}\text { Primarily predictable } \\
\text { (actions) }\end{array}$ & $\begin{array}{l}\text { Primarily predictable } \\
\text { (rules) }\end{array}$ & Variable \\
\hline $\begin{array}{l}\text { Influence of Situational } \\
\text { Factors }\end{array}$ & $\begin{array}{l}\text { Low to moderate. Prior } \\
\text { experience with process } \\
\text { or task likely to domi- } \\
\text { nate influence }\end{array}$ & $\begin{array}{l}\text { Low to moderate. Prior } \\
\text { experience with process } \\
\text { or task likely to domi- } \\
\text { nate influence }\end{array}$ & $\begin{array}{l}\text { Extrinsic factors likely } \\
\text { to dominate. }\end{array}$ \\
\hline $\begin{array}{l}\text { Ease of Detection (of the } \\
\text { error) }\end{array}$ & $\begin{array}{l}\text { Detection usually rapid } \\
\text { and effective. }\end{array}$ & $\begin{array}{l}\text { Difficult. } \\
\text { requires } \\
\text { intervention. }\end{array}$ & $\begin{array}{l}\text { Difficult. } \\
\text { requires } \\
\text { intervention. }\end{array}$ \\
\hline
\end{tabular}




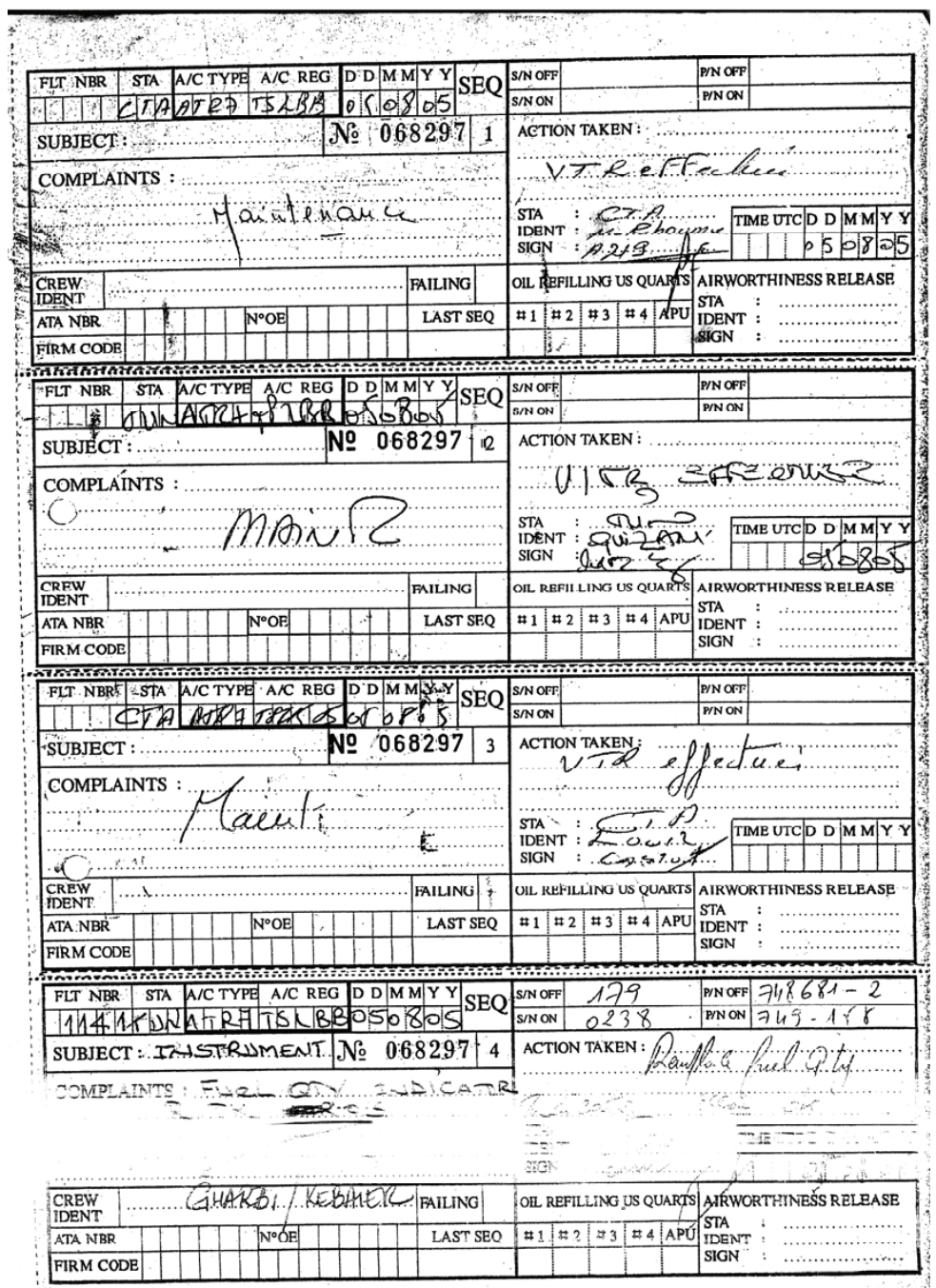

Fig. 1. ATR 72 TS-LBB maintenance logbook 


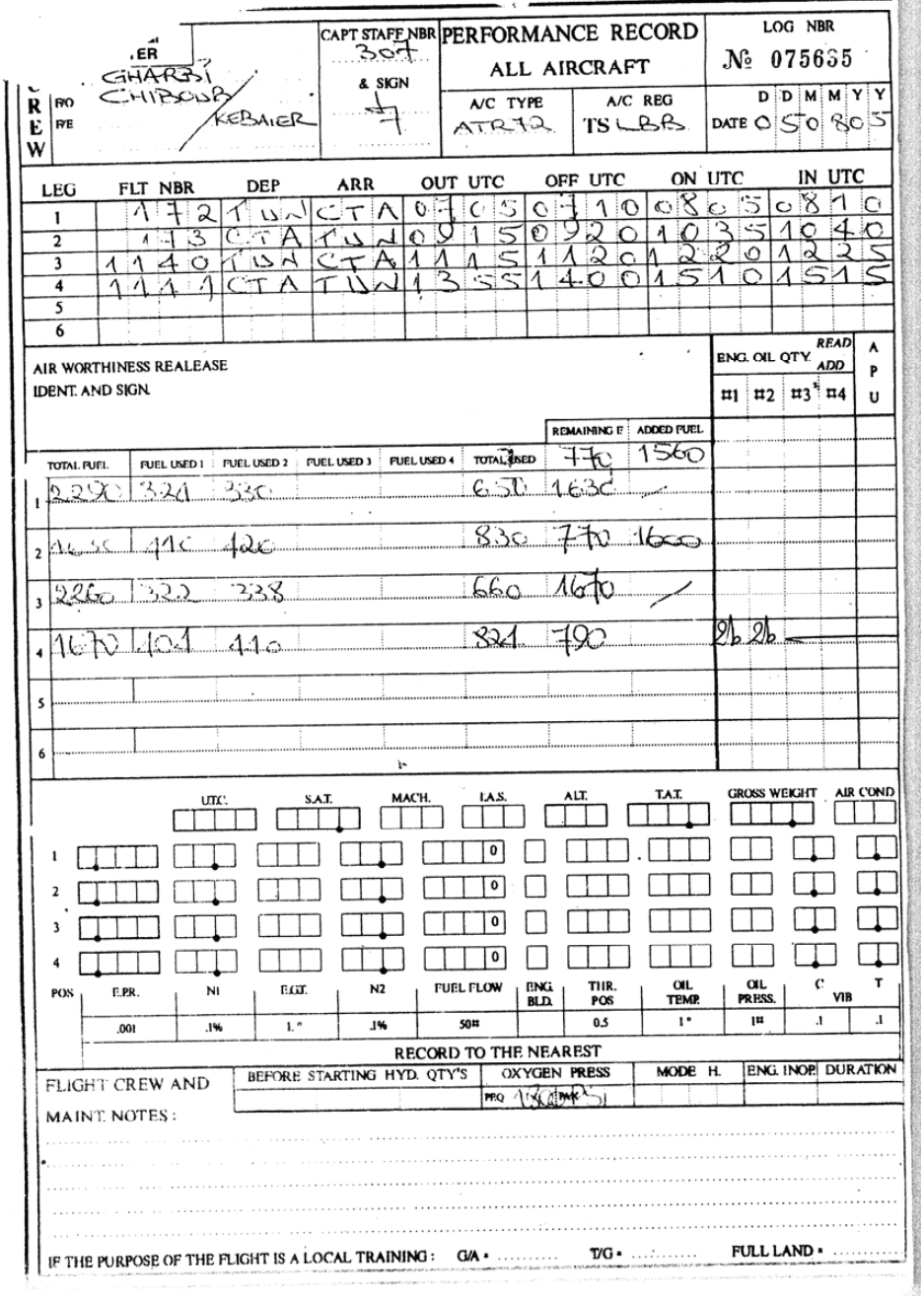

Fig. 2. ATR 72 TS-LBB performance record book 


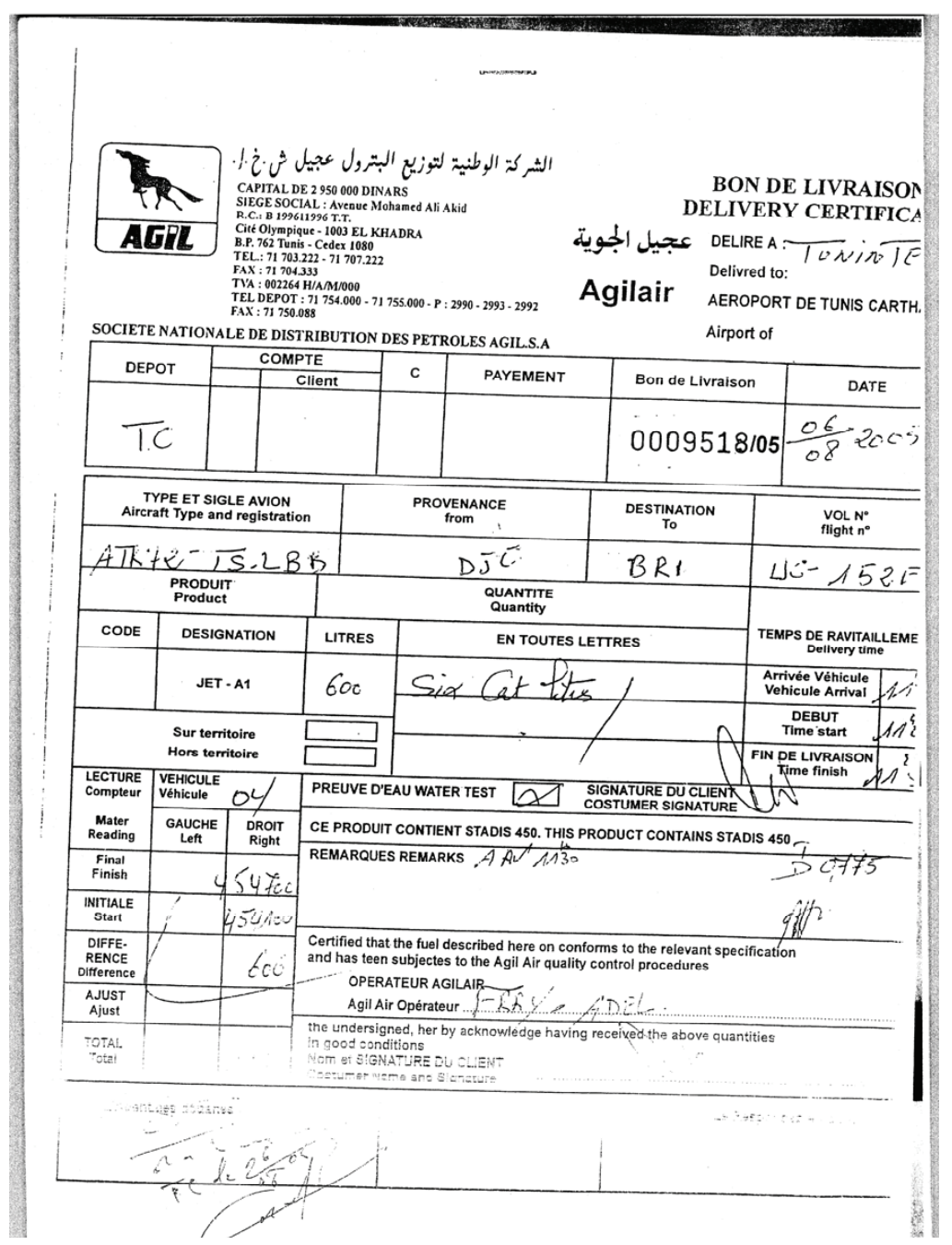

Fig. 3. ATR 72 TS-LBB refuelling document for flight Tunis-Bari 


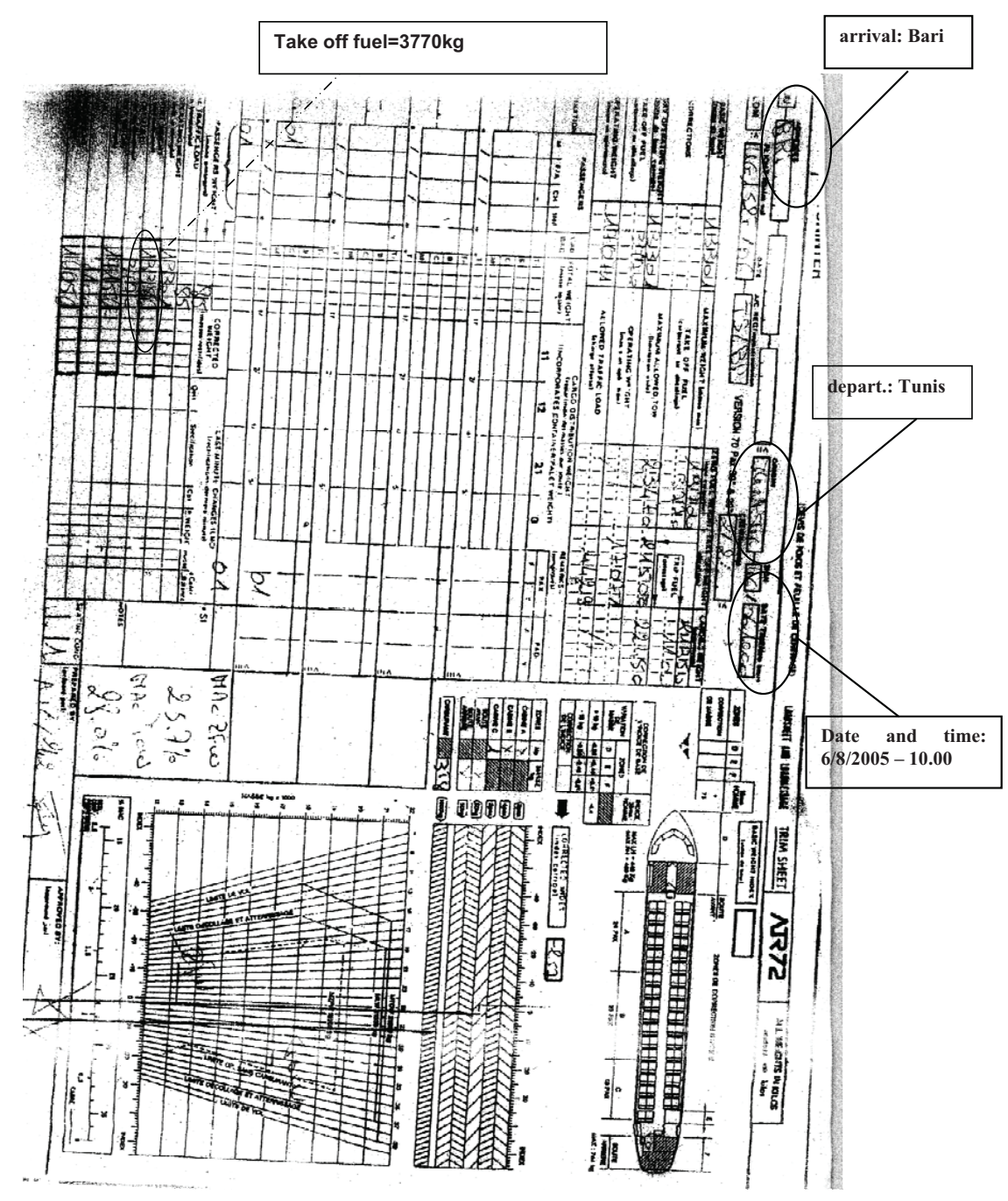

Fig. 4. Load sheet and trim for ATR 72 (flight Tunis-Bari) 


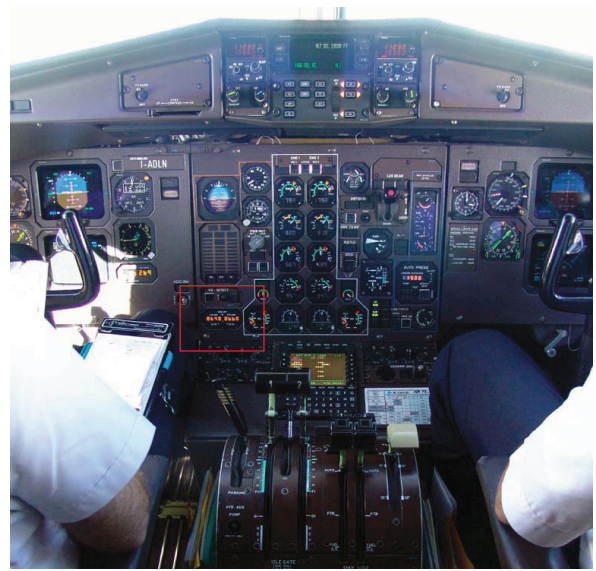

(a) Cockpit location of FQI on board of ATR 72

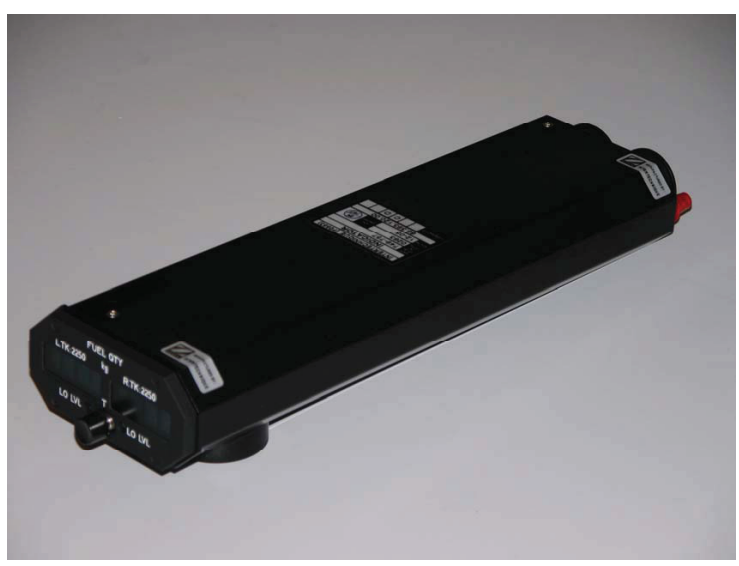

(b) ATR 42/72 fuel quantity indicator (assembly view)
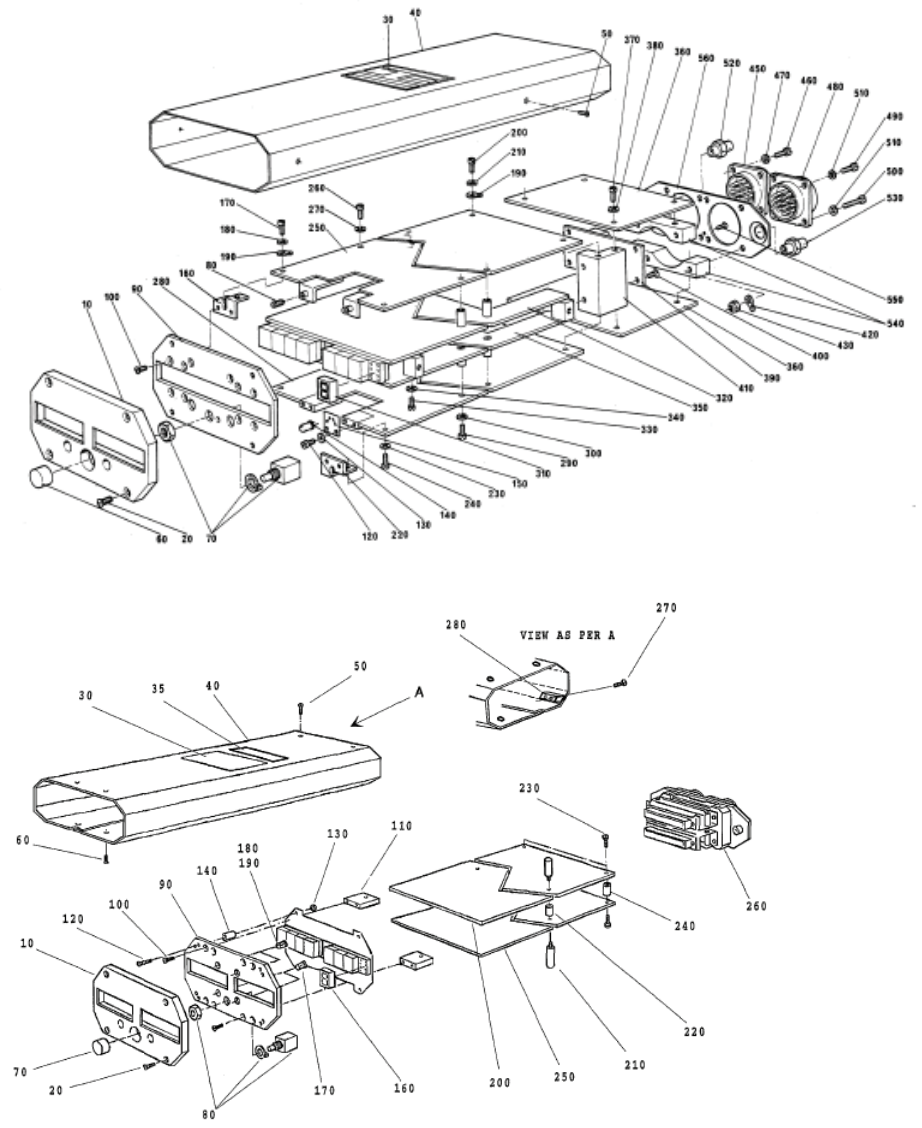

(c) ATR 42/72 fuel quantity indicator (components view)

Fig. 5. FQI on board of ATR 


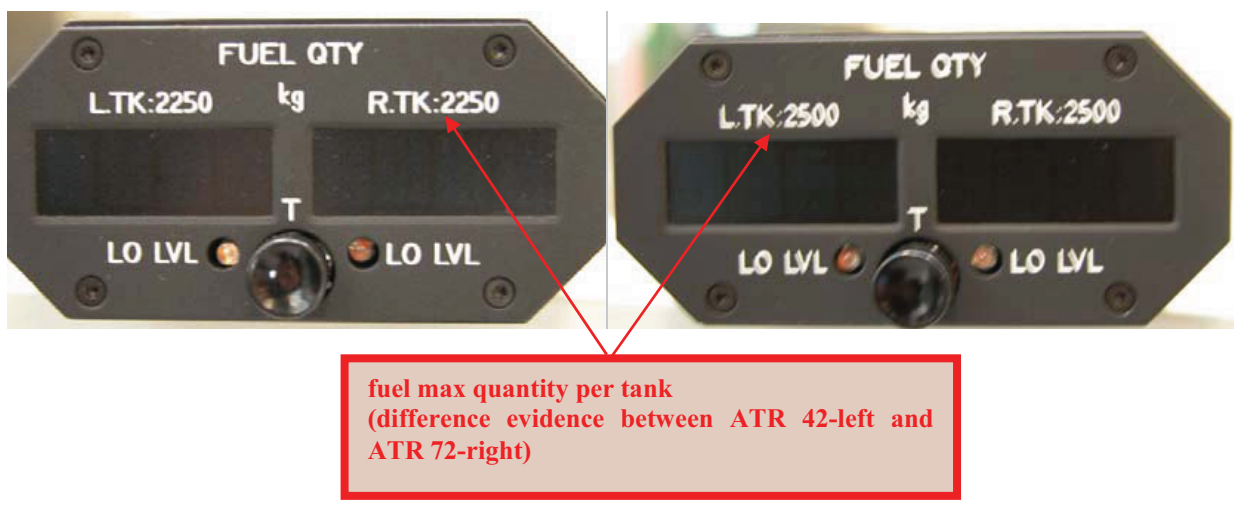

(a) ATR FQIs cartridges

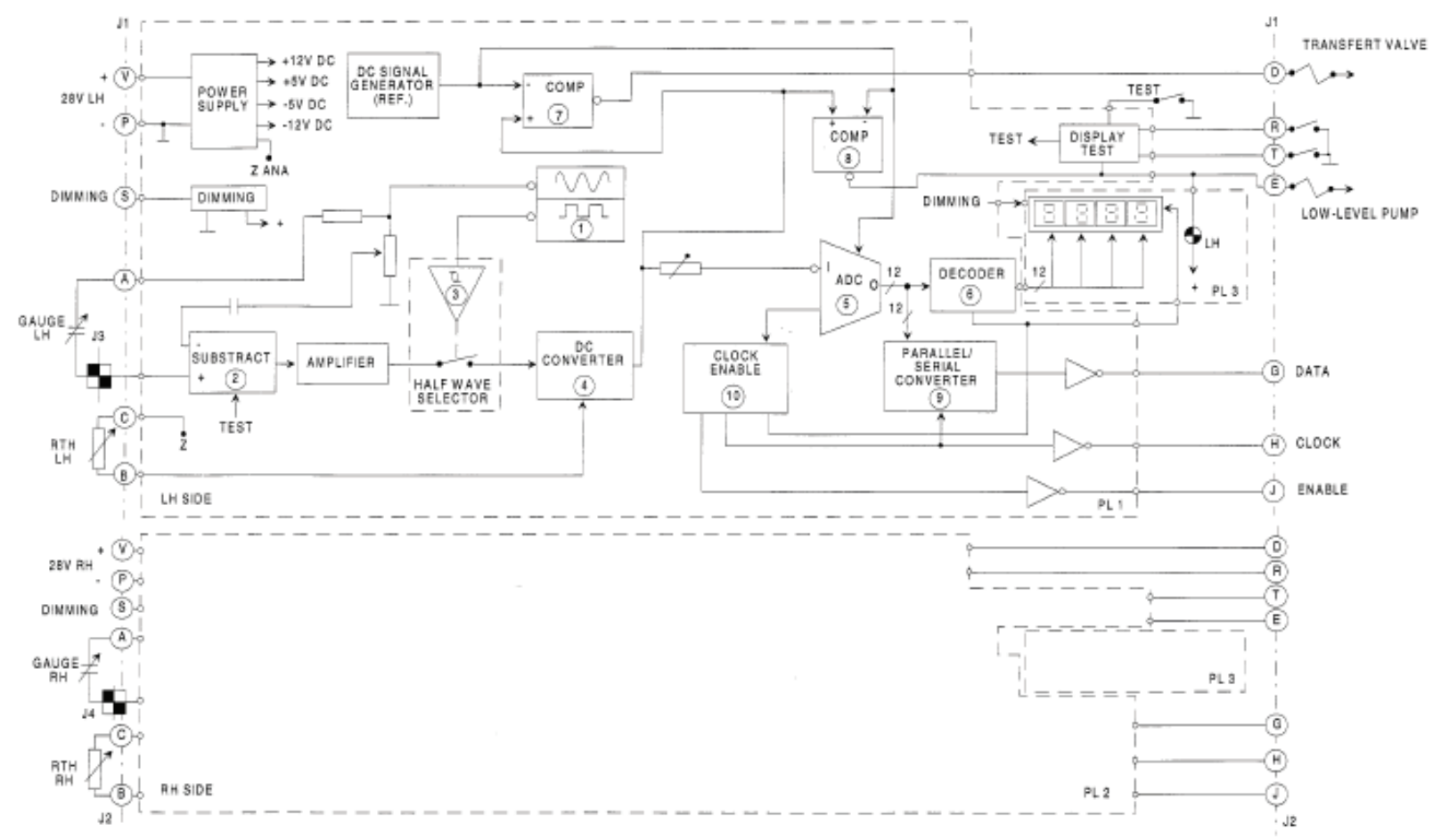

(b) FQIs block diagram for both ATR 42 and ATR 72

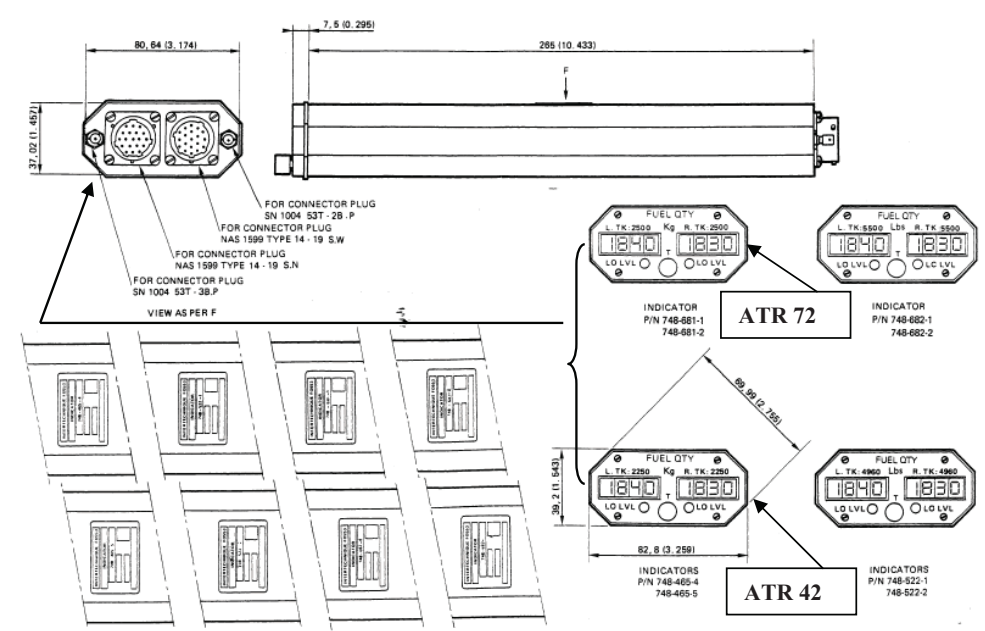

(c) ATR 42/72 fuel quantity indicator plug-ins ((note the same connection plug-ins!))

Fig. 6. Similarity and difference evidences between ATR 42 and ATR 72 FQIs (the FQIs of the ATR 42 and the ATR 72 show exterior and interior differences being the former the part/number $(\mathrm{P} / \mathrm{N})$ and serial/number $(\mathrm{S} / \mathrm{N})$ on the cartridge identification label and the hardware circuital components the latter) 


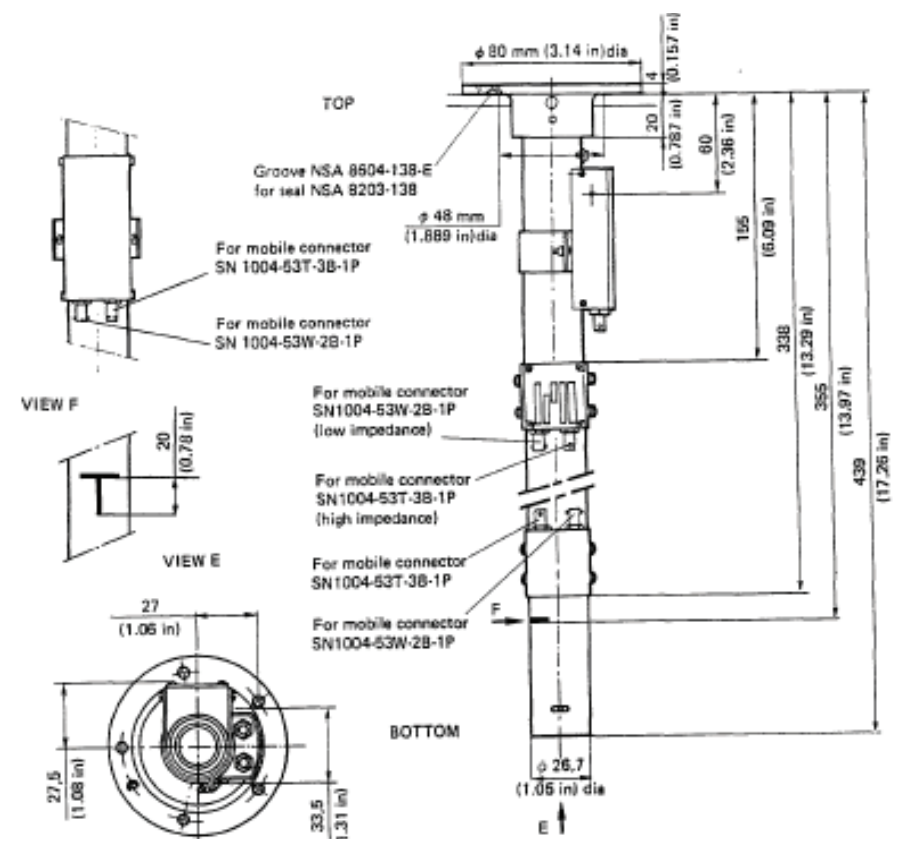

Fig. 7. Fuel probe no1 ATR42 798038 empty capacitance $6,4 \mathrm{pF}$ 


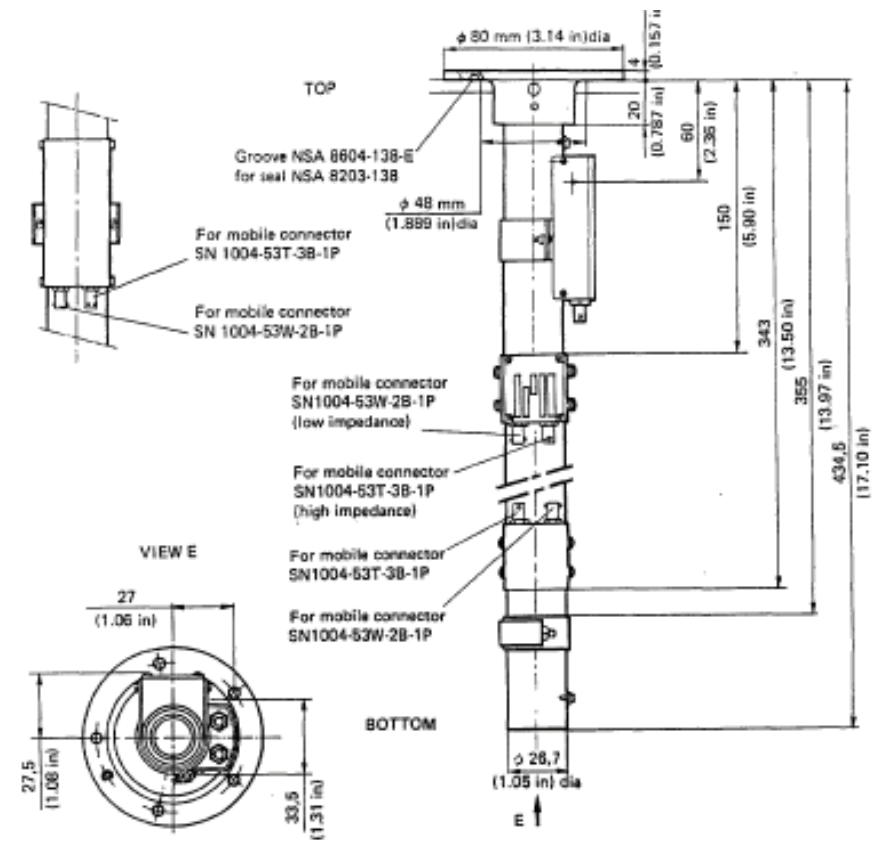

Fig. 8. Fuel probe no1 ATR72 766983-1 empty capacitance 8,55pF (with low-level sensor) 


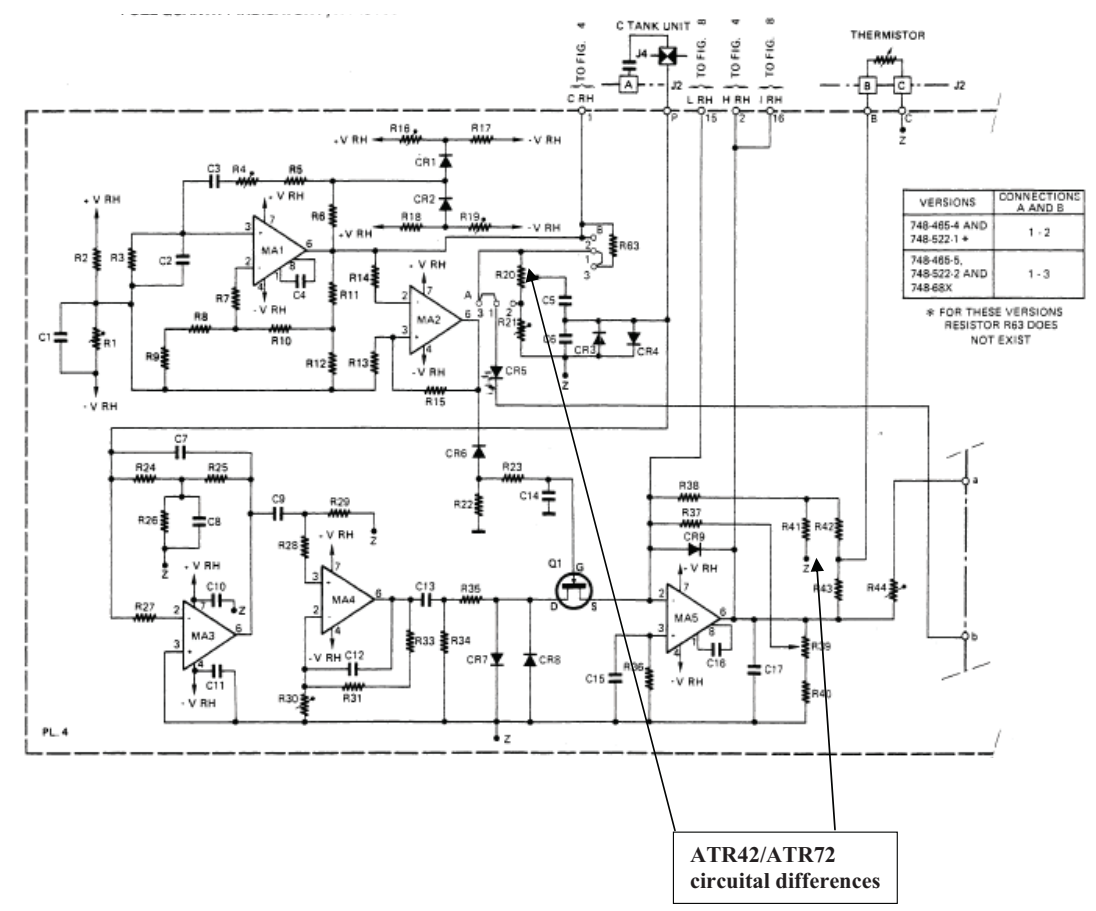

Fig. 9. Non ETOPS FQIs: circuital-probes differences between ATR 42 and ATR 72 (different hardware circuital components are present (the values of resistances R20, R21, R41 for the chain of diodes MA1, MA2, MA4, MA5)) 


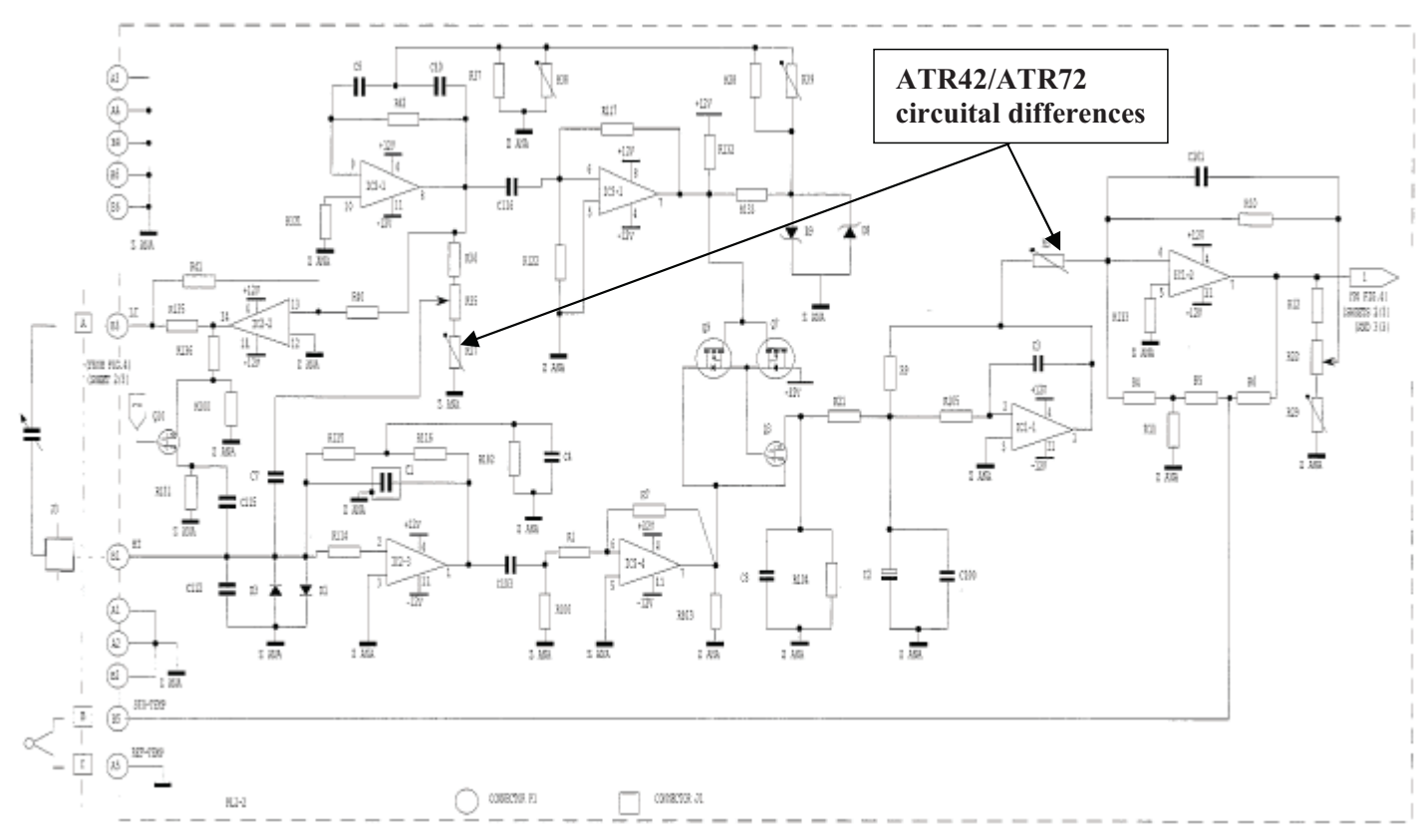

Fig. 10. ETOPS FQIs: circuital-probes differences between ATR 42 and ATR 72 


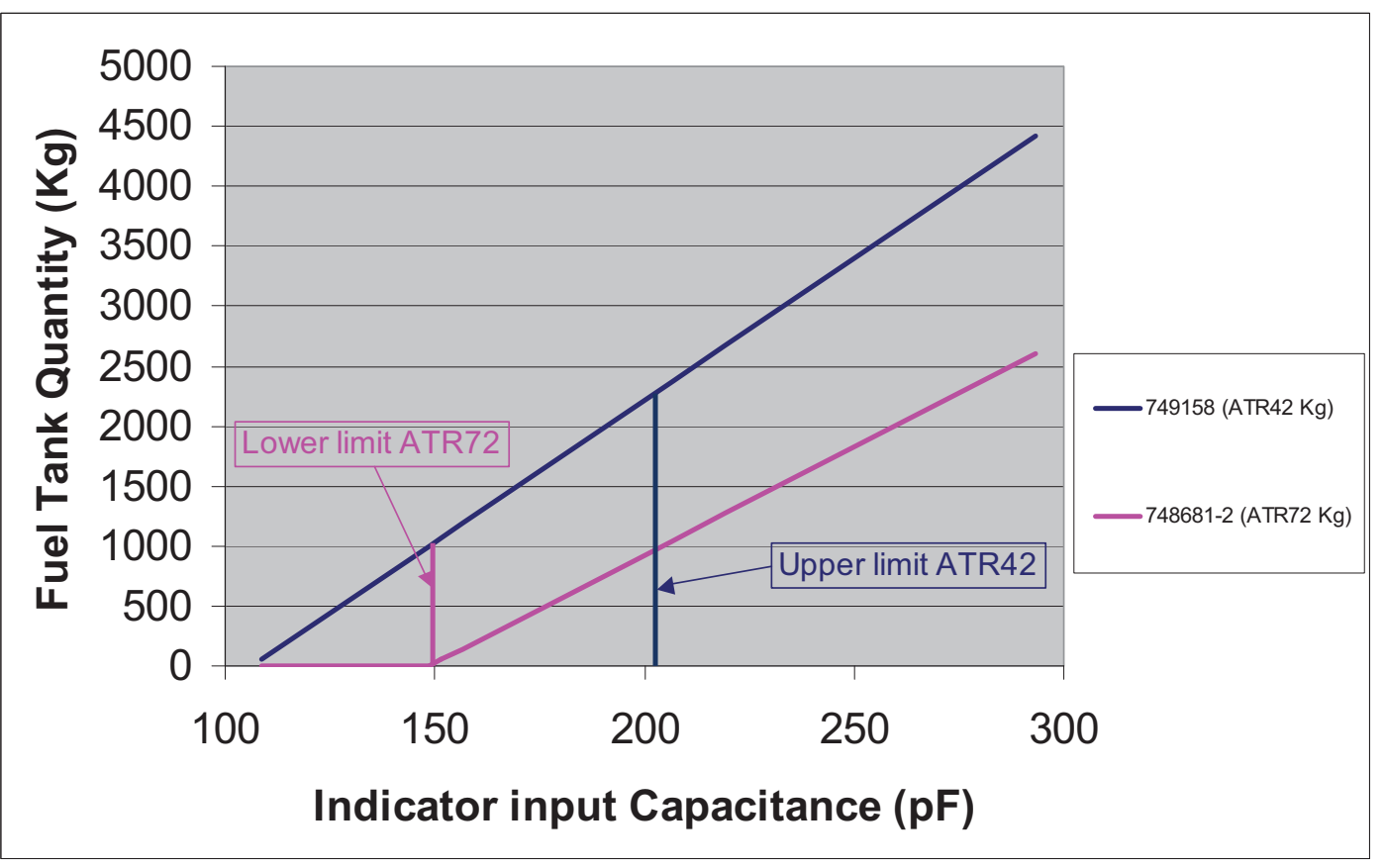

Fig. 11. Comparison diagram (fuel vs capacitance) between FQI P/N 748681-2 (ATR 72) and P/N 749158 (ATR 42) 


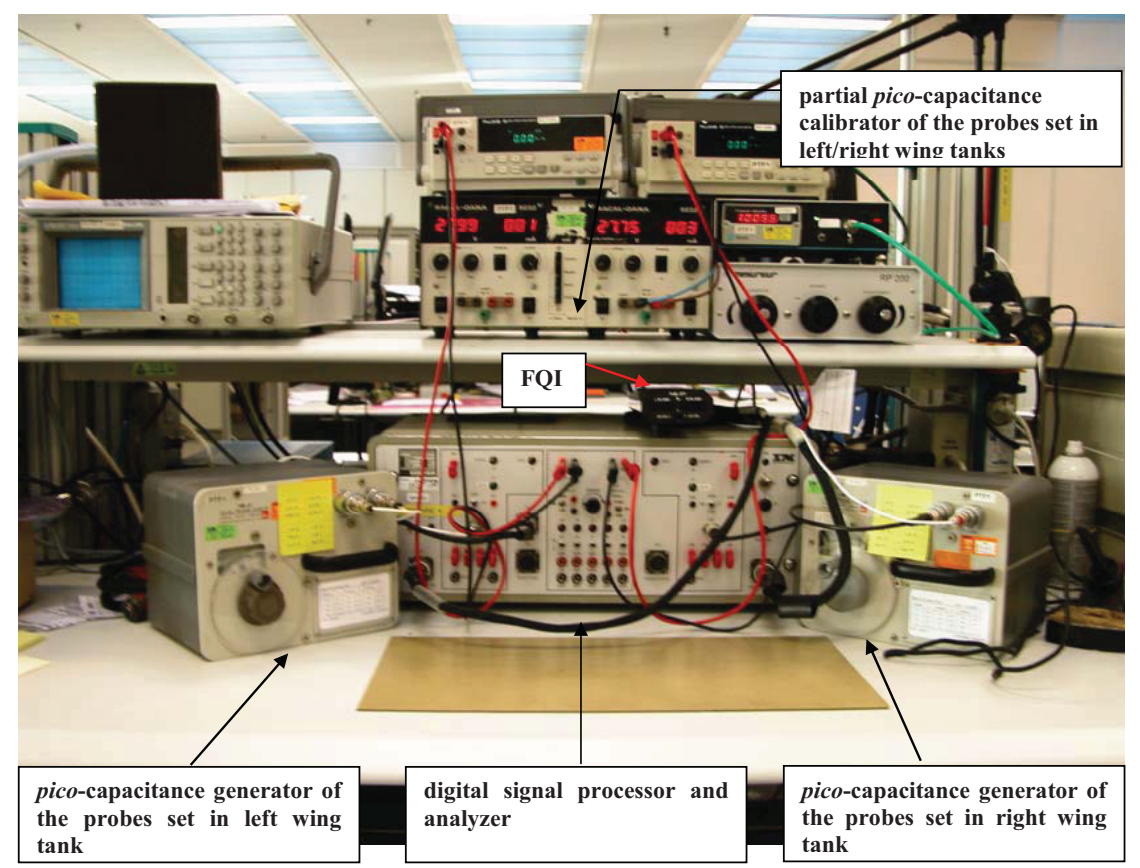

Fig. 12. Test-bench (ATP 03P252) for FQI (ATR 72 and ATR 42) performance and functioning at Intertechnique facility (Paris, France) 


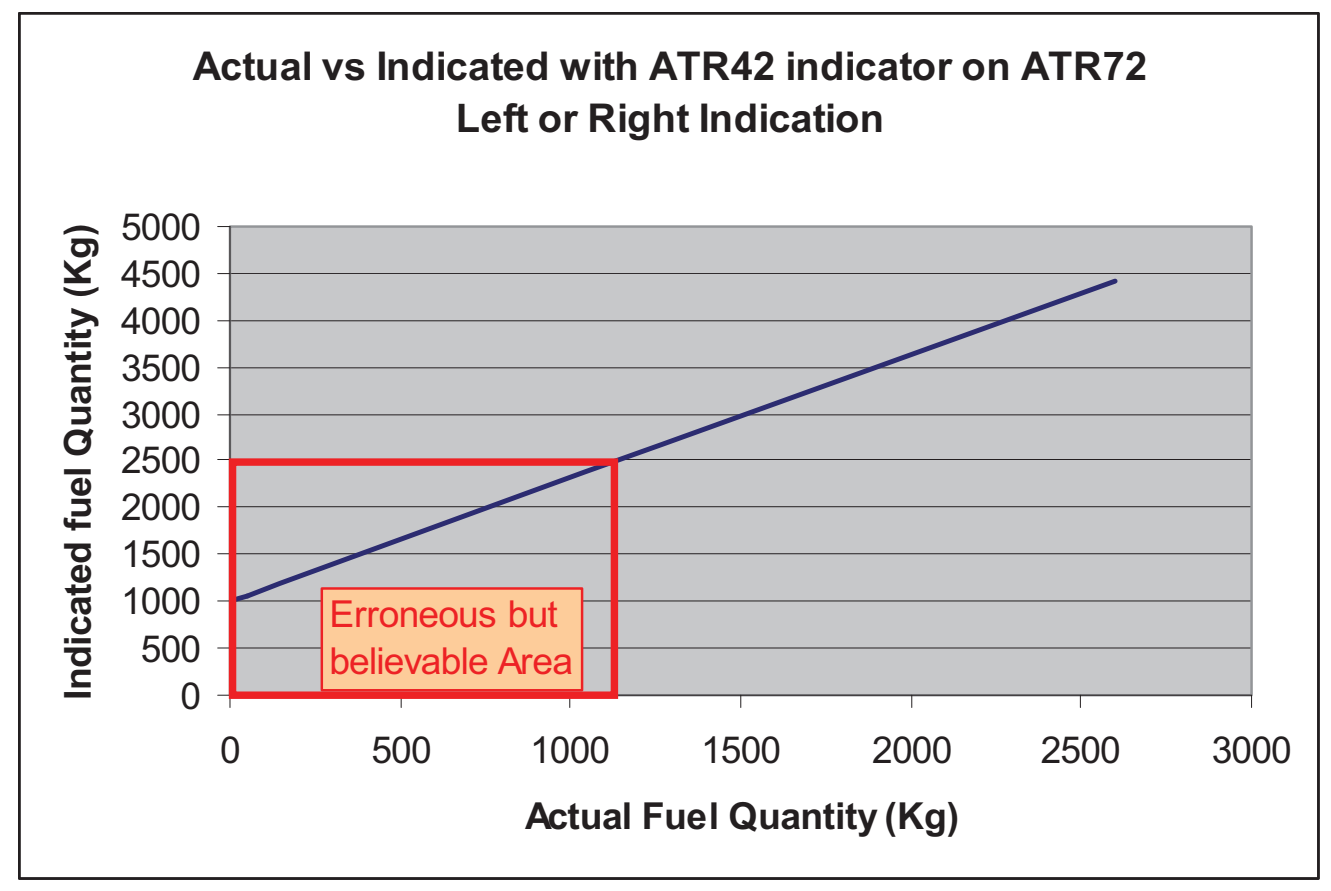

Fig. 13. Effect of incorrect replacement between FQI 749158 (ATR 42) and FQI 748681-2 (ATR 72): fictitious fuel quantity vs real fuel quantity (for each tank) 